\title{
Fabrication of porous blocks of calcium phosphate through hydrothermal processing under glycine coexistence
}

\author{
Giichiro KAWACHI, Hidetoshi MISUMI, ${ }^{*}$ Hirotaka FUJIMORI, ${ }^{*}$ Seishi GOTO, ${ }^{*}$ \\ Chikara OHTSUKI, ${ }^{* *}$ Masanobu KAMITAKAHARA ${ }^{* * *}$ and Koji IOKU ${ }^{* * *, \dagger}$ \\ School of Dentistry, Kyushu University, 3-1-1 Maidashi, Higashi-ku, Fukuoka 812-8582 \\ ${ }^{*}$ Graduate School of Medicine, Yamaguchi University, 2-16-1 Tokiwadai, Ube 755-8611 \\ ${ }^{* *}$ Graduate School of Engineering, Nagoya University, Furo-cho, Chikusa-ku, Nagoya 464-8603 \\ *** Graduate School of Environmental Studies, Tohoku University, 6-6-20 Aoba, Aramaki, Aoba-ku, Sendai 980-8579
}

\begin{abstract}
Porous hydroxyapatite (HA) and beta-tricalcium phosphate ( $\beta$-TCP) blocks are well known biomaterials employed as bone substitutes. Control of the porosity and morphology of these ceramics are important in governing their biological properties upon implantation. One synthetic method, hydrothermal processing, produces porous ceramics with distinct morphologies. In the present study, porous calcium phosphate blocks with unique structures were produced from compacted powder mixtures of alpha-tricalcium phosphate $(\alpha-\mathrm{TCP})$ and glycine (Gly) treated by exposure to water vapor at 120,160 , and $200^{\circ} \mathrm{C}$ for $5 \mathrm{~h}$. Hydrothermal treatment at $200^{\circ} \mathrm{C}$ for $5 \mathrm{~h}$ of mixtures of Gly/ $\alpha$-TCP with mass ratios of $50 / 50$ and $67 / 33$ could give the porous materials of single phase HA. The obtained porous HA blocks had micrometer-sized pores due to the entanglement of rod-shaped particles, and large-sized pores of over $100 \mu \mathrm{m}$ in diameter derived from Gly. After the heating at $900^{\circ} \mathrm{C}$ for $3 \mathrm{~h}$ in air, $\mathrm{HA}$ was converted to $\beta$-TCP with almost same microstructure in comparison with that of pre-heating one. The present methods provided insight into the production of porous blocks composed of rod-shaped calcium phosphate particles with both submicron-sized pores and large-sized pores of about $100 \mu \mathrm{m}$ in size.
\end{abstract}

(2010 The Ceramic Society of Japan. All rights reserved.

Key-words : Calcium phosphate, Hydroxyapatite, $\beta$-TCP, Hydrothermal, Rod-shaped crystal, Replica

[Received April 27, 2009; Accepted May 20, 2010]

\section{Introduction}

Calcium phosphate ceramics such as hydroxyapatite $\left(\mathrm{Ca}_{10}\left(\mathrm{PO}_{4}\right)_{6}(\mathrm{OH})_{2} ; \mathrm{HA}\right)$ and beta-tricalcium phosphate $(\beta$ $\mathrm{Ca}_{3}\left(\mathrm{PO}_{4}\right)_{2} ; \beta$-TCP) are known to have excellent biological affinity when they are implanted in the bone, ${ }^{1)-4)}$ and hence they are widely used as an artificial bone substitute in bone tissue repairs. In the designing of porous calcium phosphate ceramics for bone regeneration, it is important to control their pore structures. Pores with suitable size are required for both cells penetration into material matrix and adsorption of proteins etc. which play important rolls in vivo. Thus, the study of fabrication processes for controlling ceramic microstructure is valuable for the design and refinement of novel biomaterials. Porous ceramic blocks are generally produced by sintering with an organic template which decomposes during heating at high temperature to yield pores, but such conventional sintering methods hardly allow control of the resulting ceramic microstructures. In contrast, hydrothermal processing enables formation of well crystallized ceramics with unique microstructures depending on their crystal habit. Among the types of synthetic procedures for producing HA, hydrothermal processing is interesting for its easy fabrication of micrometer-sized rod-shaped crystals at temperatures below $200^{\circ} \mathrm{C}^{5)-9)}$ Ioku et al. have fabricated rod-shaped HA through hydrothermal processing in which compacted powdered $\alpha$-tricalcium phosphate $\left(\alpha-\mathrm{Ca}_{3}\left(\mathrm{PO}_{4}\right)_{2} ; \alpha\right.$-TCP) was exposed to hydrothermal vapor and completely transformed into a calcium-deficient HA after the treatment at temperatures above

Corresponding author: K. Ioku; E-mail: ioku@mail.kankyo. tohoku.ac.jp $120^{\circ} \mathrm{C}$ for $3 \mathrm{~h} .{ }^{10)}$ The synthesized HA was an agglomeration of rod-shaped crystals less than $20 \mu \mathrm{m}$ in length with the aspect ratio of about 10, and locked together to form micrometer-sized pores. Under these conditions, coagulation of crystal particles results in formation of a porous structure and calcium-deficient HA porous ceramics prepared from $\alpha$-TCP have shown higher biodegradability and induced higher bone formation in rabbit femur than stoichiometric HA porous ceramics prepared by conventional sintering methods. ${ }^{11)}$ Unfortunately, the conditions suitable for preparation of porous ceramic blocks are not well understood. ${ }^{12)}$ Previous papers have reported that micrometer-sized pores ${ }^{13)}$ as well as large-sized pores over about $100 \mu \mathrm{m}^{14)-16)}$ are important features in bone-repairing materials to promote bone formation.

In the present study, we investigated the conditions required for preparation of porous blocks with sub-micrometer-sized pores and large-sized pores more than $100 \mu \mathrm{m}$ in size through hydrothermal treatment of $\alpha$-TCP. Large-sized pore formation was accomplished by incorporation of glycine (Gly) particles as the replica method, chosen for their harmless character and water solubility, and porous HA ceramics prepared under hydrothermal conditions were examined to determine their microstructure and mechanical properties. In addition, porous $\beta$-TCP ceramics with the similar structure was prepared using a subsequent heating treatment at $900^{\circ} \mathrm{C}$ in air. The relationship between the microstructure and synthetic conditions of these ceramics are discussed.

\section{Experimental procedure}

The powder of $\alpha$-TCP (Taihei Chemical Industrial Co., Ltd., Japan.) was mixed with different amounts of Gly $\left(\mathrm{H}_{2} \mathrm{NCH}_{2} \mathrm{COOH}\right.$, Wako Pure Chemical Industries, Ltd., Japan) in mass ratios of Gly $/ \alpha$-TCP at $0 / 100,50 / 50,67 / 33$, and $75 / 25$, 
with estimated volume ratios of $0 / 100,71 / 29,83 / 17$, and $88 / 12$, respectively, assuming the density of Gly and $\alpha$-TCP at 1.16 and $2.86 \mathrm{~g} \cdot \mathrm{cm}^{-3}$, respectively. A slurry composed of $\alpha$-TCP and Gly was prepared by mixing for several minutes in a porcelain mortar with addition of appropriate amounts of ethanol. After drying, the resulting mixture was compressed at $200 \mathrm{MPa}$ of uniaxial pressure to form a powder pellet of $8.0 \mathrm{~mm}$ diameter and $4.5 \mathrm{~mm}$ length and then the pellets were hydrothermally treated in a specially designed autoclave (Shikokurika, Japan, Fig. 1). Here, a compacted specimen was placed in a $100 \mathrm{~cm}^{3}$ autoclave with $20 \mathrm{~cm}^{3}$ of ultrapure water and then heated at 120,160 , or $200^{\circ} \mathrm{C}$ for $5 \mathrm{~h}$. After the vessel was cooled to room temperature, the specimen removed, rinsed with ultrapure water, and dried at $100^{\circ} \mathrm{C}$ in air. Some specimens were subsequently heated at $900^{\circ} \mathrm{C}$ for $3 \mathrm{~h}$ in air.

Total porosity of the specimens was determined by the measurement of mass and size of the specimens, assuming that all of the solid would be a single phase of stoichiometric HA $\left(3.16 \mathrm{~g} \cdot \mathrm{cm}^{-3}\right)$. The morphology of gold sputtered specimens was observed by scanning electron microscope (SEM) at $15 \mathrm{kV}$. The pore size distribution of specimens was estimated by the intercepting method using SEM observation of polished surface. The particle size distribution of Gly as the starting material was obtained by SEM observation. The size was measured as the longest length in diameter. The phases of the specimens were

(a)

$120^{\circ} \mathrm{C}$
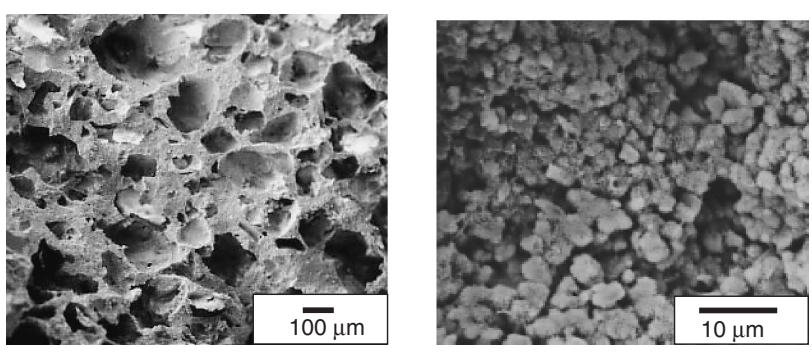

$160^{\circ} \mathrm{C}$
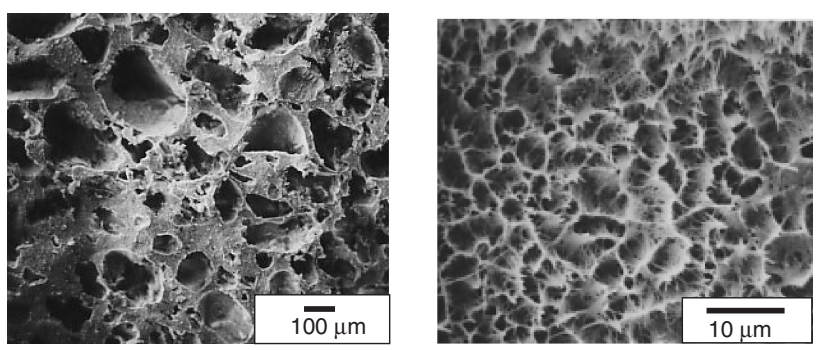

$200{ }^{\circ} \mathrm{C}$
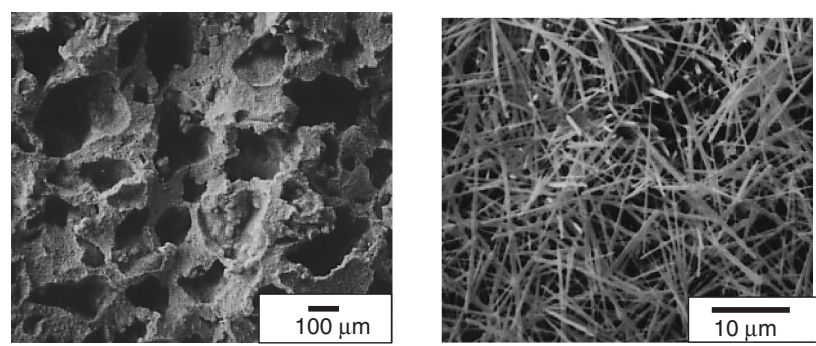

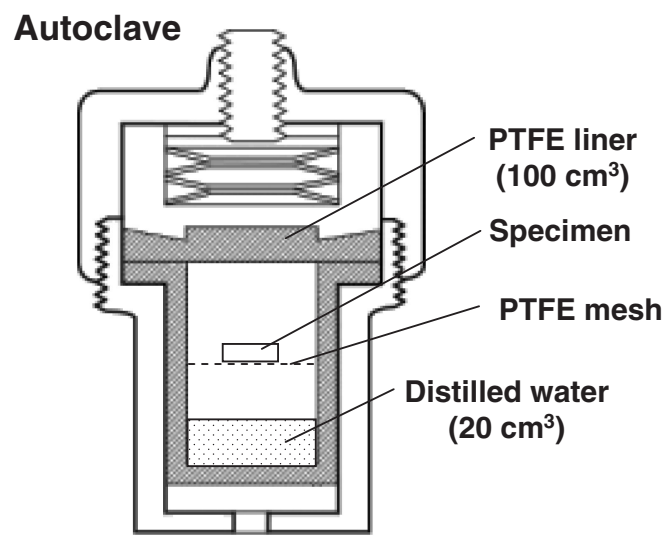

Fig. 1. Apparatus for hydrothermal treatment.

identified by powder X-ray diffraction (XRD) with $\mathrm{CuK} \alpha$ radiation, operating at $40 \mathrm{kV}$ and $20 \mathrm{~mA}$, and phase identification accomplished using a search and match program with the data bank of the International Center for Diffraction Data (ICDD). The atomic ratios of $\mathrm{Ca} / \mathrm{P}$ in the synthesized specimens were estimated by using XRD. ${ }^{17)-19)}$ In the past research, it was reported that nonstoichiometric HA with calcium deficient composition fully decomposed into stoichiometric $\mathrm{HA}(\mathrm{Ca} /$

(b)
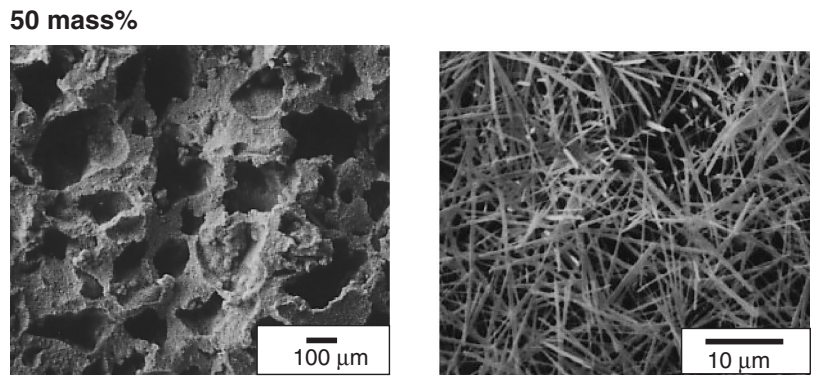

67 mass $\%$
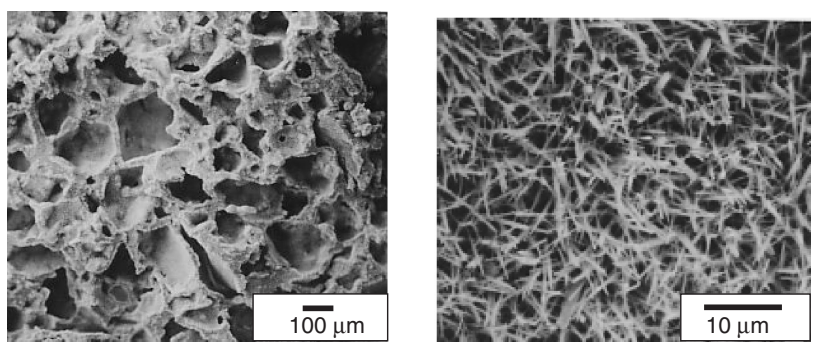

75 mass $\%$
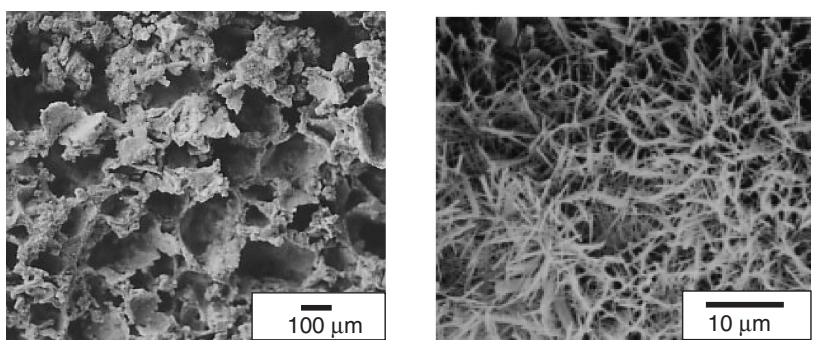

Fig. 2. SEM images of fractured sections of (a) specimens $(\mathrm{Gly} / \alpha-\mathrm{TCP}=50 / 50)$ after hydrothermal treatment at indicated temperatures for $5 \mathrm{~h}$, (b) specimens with indicated addition of Gly after hydrothermal treatment at $200^{\circ} \mathrm{C}$ for $5 \mathrm{~h}$. 
$\mathrm{P}=1.67)$ and $\beta$-TCP $(\mathrm{Ca} / \mathrm{P}=1.50)$ after heating at $900^{\circ} \mathrm{C}$ for $3 \mathrm{~h}$ in air. The relative intensity of XRD lines of HA $\left(2 \theta=31.8^{\circ}\right)$ and $\beta$-TCP $\left(2 \theta=31.0^{\circ}\right)$ could give the $\mathrm{Ca} / \mathrm{P}$ ratios by comparing it with the analytical curve prepared previously. ${ }^{18), 19)}$ In addition, Ioku et al. has reported that $\mathrm{Ca} / \mathrm{P}$ atomic ratios were very similar to values determined by chemical analysis with inductively coupled plasma spectroscopy of rod-shaped HA. ${ }^{10}$ )

Mechanical strength was estimated by measuring the compressive strength of specimens at a loading rate of $2 \mathrm{~mm} \cdot \mathrm{min}^{-1}$ with a mechanical testing machine (TG-5kN, Minebea Co., Ltd., Japan). Compressive strength was determined by the mean values of 3 samples from each specimen at a maximum load per unit surface area before specimens failed.

\section{Results}

The SEM images at lower magnification of fractured sections of specimens prepared through hydrothermal treatment of a mixture of $\alpha$-TCP and Gly showed that all of prepared blocks had pores of over $100 \mu \mathrm{m}$ (Fig. 2). At higher magnification, the specimen prepared at $120^{\circ} \mathrm{C}$ showed very fine particles of about $1 \mu \mathrm{m}$ on the larger particles of about $2 \mu \mathrm{m}$ in size. Networkshaped structures of fine rods were observed at higher magnification of the specimens prepared at $160^{\circ} \mathrm{C}$, while larger rods observed on the frameworks of specimens prepared at $200^{\circ} \mathrm{C}$. In the case of specimens prepared at $200^{\circ} \mathrm{C}$, the framework appeared to decrease with increasing mixed ratio of Gly $/ \alpha$-TCP from $50 / 50$ to $75 / 25$ by SEM observation. At higher magnification, rods were observed in all frameworks synthesized at $200^{\circ} \mathrm{C}$.

Patterns of XRD of specimens prepared through hydrothermal treatment of mixtures of $\alpha$-TCP and Gly showed that specimens synthesized with mixed ratio of Gly $/ \alpha$-TCP of $50 / 50$ and prepared at $120^{\circ} \mathrm{C}$ showed peaks assigned to HA in addition to peaks assigned to $\alpha$-TCP and Gly (Fig. 3). In specimens prepared at $160^{\circ} \mathrm{C}$, no peaks could be assigned to $\alpha$-TCP but distinct peaks were assigned to Gly, as well as a small signal related to $\beta$-TCP. Only peaks assigned to HA were detected in specimens prepared at $200^{\circ} \mathrm{C}$. The residual Gly in products decreased with increasing treatment temperature. Small amount of monetite $\left(\mathrm{CaHPO}_{4}\right)$ was detected in specimens prepared without Gly. No $\alpha$-TCP was detected in the specimens prepared from Gly $/ \alpha$-TCP mixtures at mass ratios of 50/50 and higher, but at $75 / 25$ a little Gly persisted in the specimens. Overall, porous blocks consisting of rod-shaped HA were fabricated after hydrothermal treatment at temperatures over $160^{\circ} \mathrm{C}$ for $5 \mathrm{~h}$. No residual Gly were detected in all specimens after hydrothermal treatment at $200^{\circ} \mathrm{C}$ for $5 \mathrm{~h}$.

According to SEM images of fractured sections of specimens after heating at $900^{\circ} \mathrm{C}$ for $3 \mathrm{~h}$ in air, microstructures of them were very similar to unheated specimens regardless of the mixed ratio of Gly $/ \alpha$-TCP (Fig. 4). Patterns of XRD of specimens showed that the crystalline phases of heated specimens were mainly $\beta$ TCP with small amount of coexisting HA (Fig. 5). There appeared to be no significant differences in the crystalline phases in specimens with different mixed ratios of Gly/ $\alpha$-TCP. From XRD measurement of heated specimens, the estimated $\mathrm{Ca} / \mathrm{P}$ atomic ratios of specimens synthesized with Gly $/ \alpha$-TCP mixed ratios at $0 / 100,50 / 50,67 / 33$, and $75 / 25$ were $1.51,1.54,1.54$, and 1.55 , respectively. The $\mathrm{Ca} / \mathrm{P}$ ratio of specimens with Gly was higher than that without Gly.

The pore size distribution in the porous blocks and the particle size distribution of Gly as the starting material were determined from SEM images at low magnification. The pore size distributions had a similar pattern to that of the size of Gly
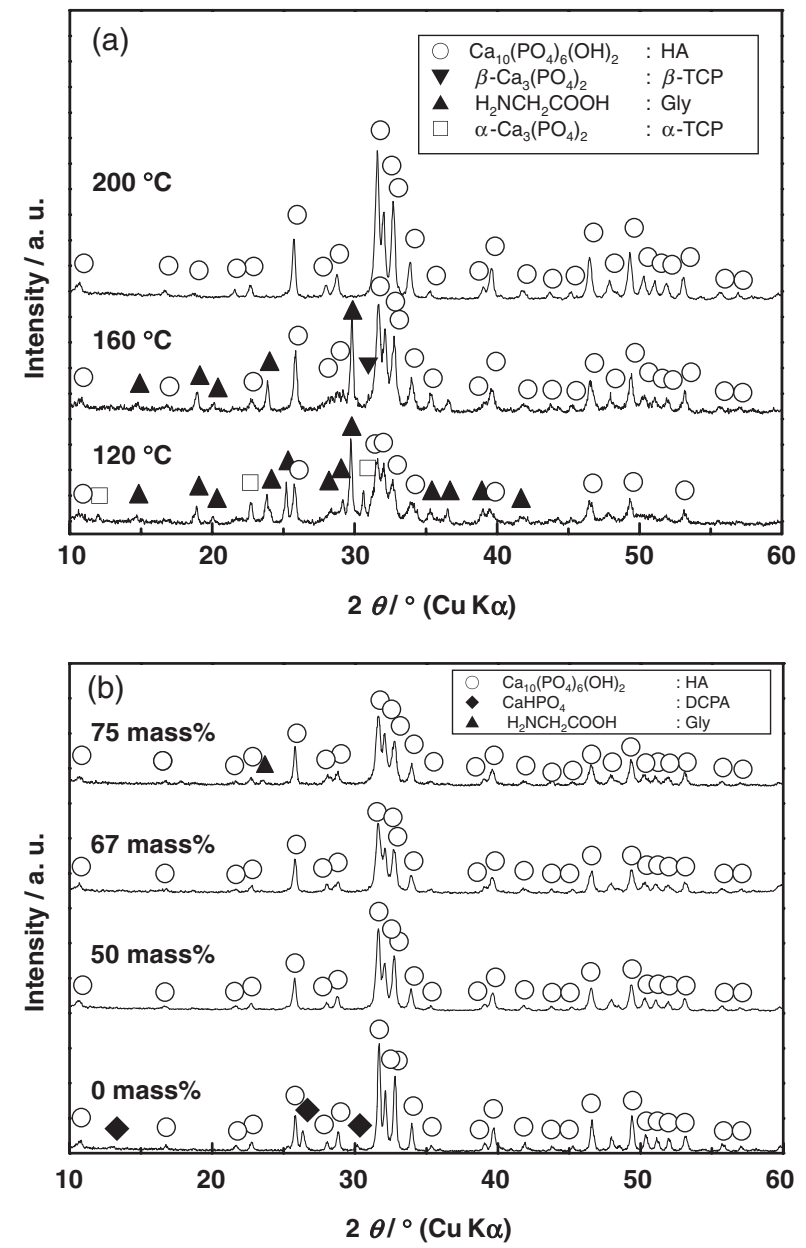

Fig. 3. Powder XRD patterns of (a) specimens $(\mathrm{Gly} / \alpha$-TCP $=50 / 50)$ after hydrothermal treatment at indicated temperatures for $5 \mathrm{~h}$, (b) specimens with indicated addition of Gly after hydrothermal treatment at $200^{\circ} \mathrm{C}$ for $5 \mathrm{~h}$

particles (Fig. 6). Pores larger than $300 \mu \mathrm{m}$ were rarely observed after heating at $900^{\circ} \mathrm{C}$, compared with unheated specimens. Relationship between volume of Gly in the powder compacts and porosity of the specimens treated hydrothermally at $200^{\circ} \mathrm{C}$ for $5 \mathrm{~h}$ showed that the calculated values of the volume of large-sized pores was related to the addition of Gly (Fig. 7, dotted line), assuming that small size pores were present in the same volume $(40 \mathrm{vol} \%)$ as in specimens prepared without Gly. Relationship between volume fraction of Gly in the powder compacts and porosity of the heated specimens was shown in Fig. 7. Porosity was evaluated using the apparent true density of mixture between HA and $\beta$-TCP based on the XRD measurement. Total porosity of compacts before and after heating was increased with increasing volume fraction of Gly. There was almost no difference of the values of total porosity between specimens before and after heating. In the case of mixed ratio of $75 / 25$, the block of HA had about $70 \%$ porosity as total porosity and about $15 \%$ porosity as framework porosity.

Compressive strength of the blocks prepared hydrothermally at $200^{\circ} \mathrm{C}$ for $5 \mathrm{~h}$ and the blocks subsequently heated at $900^{\circ} \mathrm{C}$ for $3 \mathrm{~h}$ in air were shown as a function of porosity in Fig. 8. The values of compressive strength of blocks with porosity of about $70 \%$ were over $5 \mathrm{MPa}$ that is comparable to human cortical bone. ${ }^{20)}$ 

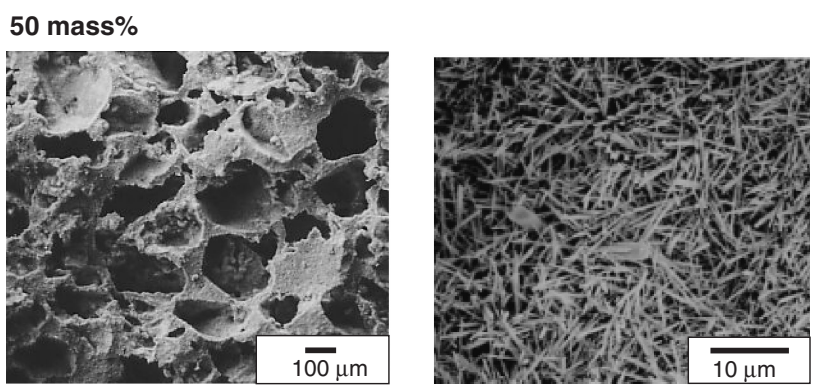

67 mass $\%$
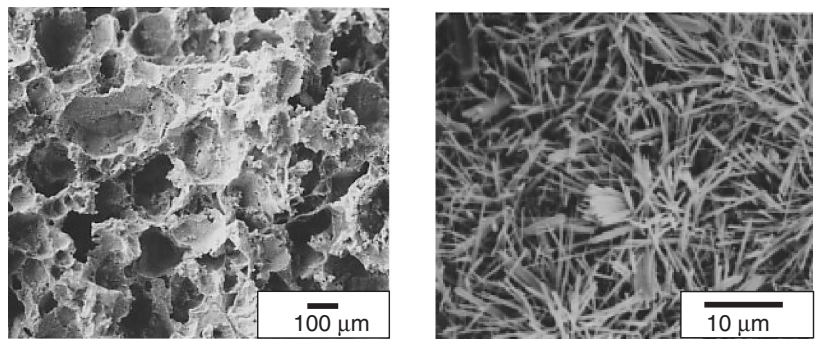

75 mass $\%$
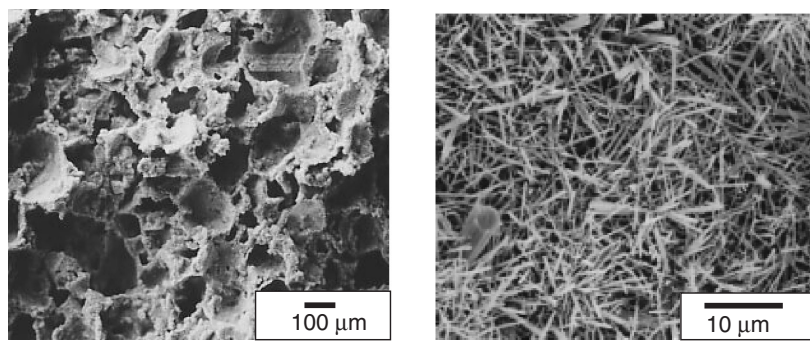

Fig. 4. SEM images (left: low magnification; right: high magnification) of fractured sections of specimens prepared from mixtures with indicated addition of Gly. Specimens were treated hydrothermally at $200^{\circ} \mathrm{C}$ for $5 \mathrm{~h}$ and then heated at $900^{\circ} \mathrm{C}$ for $3 \mathrm{~h}$ in air.

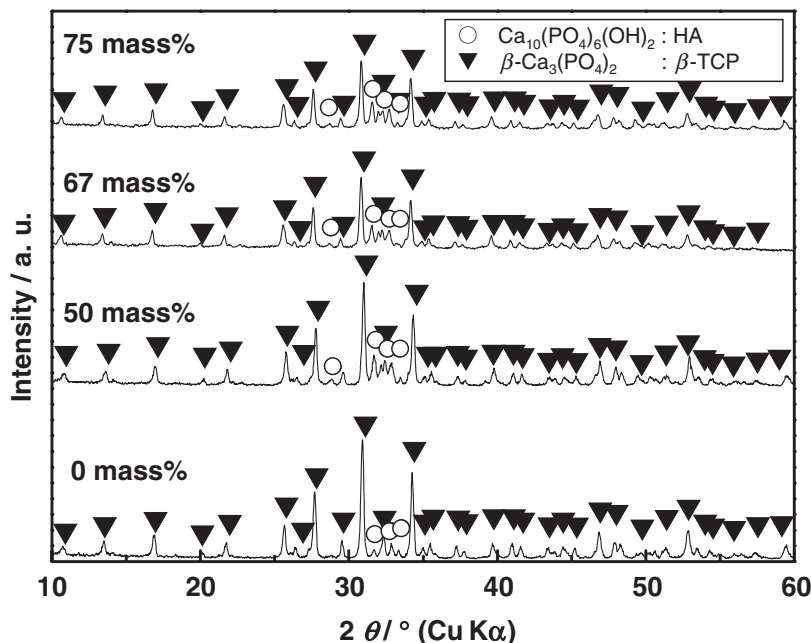

Fig. 5. Powder XRD patterns of the specimens prepared from mixtures with indicated addition of Gly. Specimens were treated hydrothermally at $200^{\circ} \mathrm{C}$ for $5 \mathrm{~h}$ and then heated at $900^{\circ} \mathrm{C}$ for $3 \mathrm{~h}$ in air.

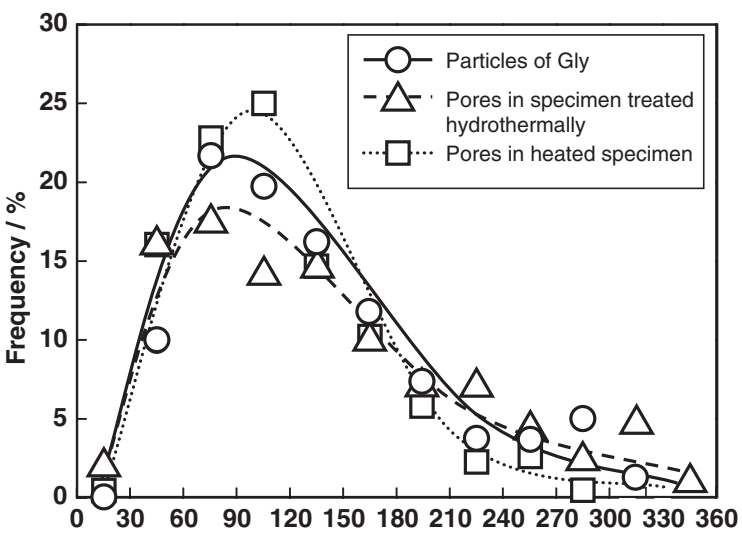

Pore size of specimens and particle size of Gly / $\mu \mathrm{m}$

Fig. 6. Distribution of the particle size of Gly $(\bigcirc)$ as the starting material and pore sizes in two types porous blocks. One of them was prepared hydrothermally from the mixture of $\mathrm{Gly} / \alpha-\mathrm{TCP}=50 / 50$ at $200^{\circ} \mathrm{C}$ for $5 \mathrm{~h}(\triangle)$ the other one was after heating at $900^{\circ} \mathrm{C}$ for $3 \mathrm{~h}$ in air of it described above $(\square)$

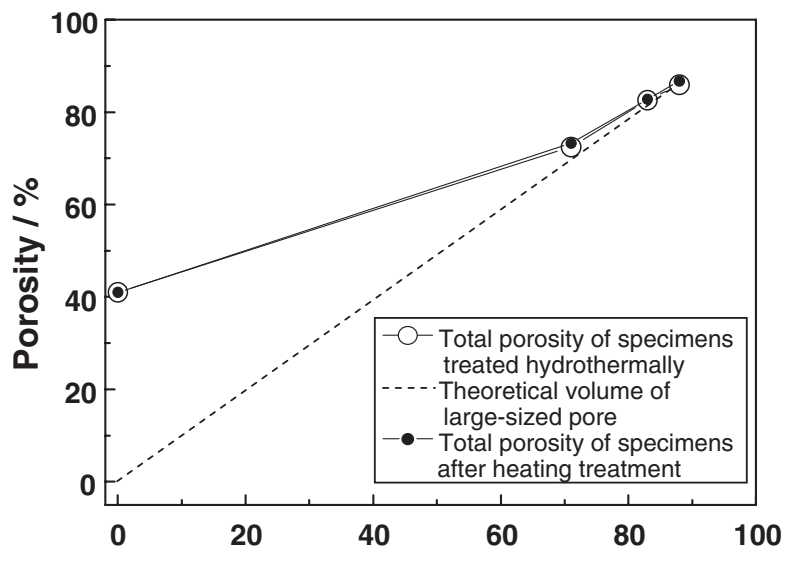

Volume fraction of Gly in starting powder / \%

Fig. 7. Relationship between the volume fraction of Gly and porosity of two types porous blocks. One of them was prepared hydrothermally at $200^{\circ} \mathrm{C}$ for $5 \mathrm{~h}(\bigcirc)$, the other one was after heating at $900^{\circ} \mathrm{C}$ for $3 \mathrm{~h}$ in air of it described above (O). Dotted line indicates calculated values of the large-sized pore volume in porous blocks, assuming the porosity derived from Gly particles.

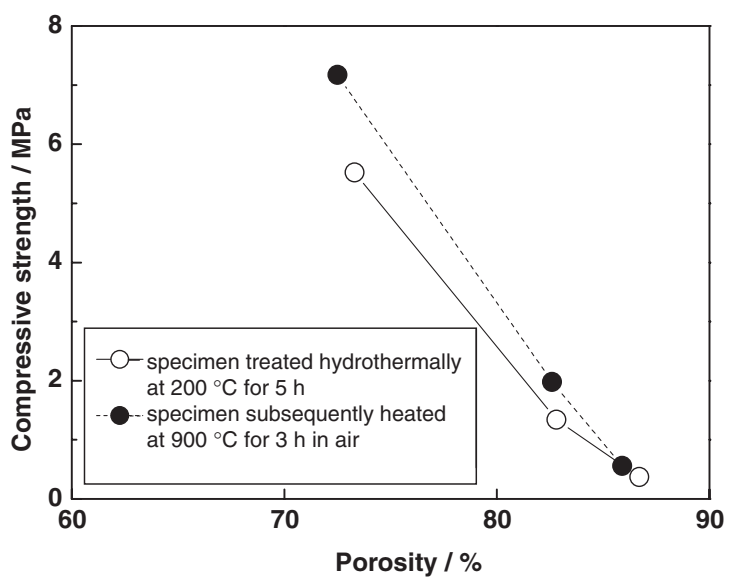

Fig. 8. Compressive strength of the blocks prepared hydrothermally at $200^{\circ} \mathrm{C}$ for $5 \mathrm{~h}(\bigcirc)$ and the blocks subsequently heated at $900^{\circ} \mathrm{C}$ for $3 \mathrm{~h}$ in air (O). 


\section{Discussion}

Porous blocks of pure calcium deficient HA were obtained through the hydrothermal vapor exposure treatment of $\alpha$-TCP and Gly mixtures at $200^{\circ} \mathrm{C}$ for $5 \mathrm{~h}$ under saturated pressure of water. The blocks of HA formed frameworks through aggregation, producing structural pores in the micrometer size range. The framework porosity of a block prepared without Gly was about $40 \mathrm{vol} \%$ (Fig. 7). Hence, the pores less than few micro meter were generally produced by hydrothermal treatment of plain $\alpha$ TCP powder compacts. The pores caused by the addition of Gly were estimated around from 50 to $300 \mu \mathrm{m}$ by SEM observation. The method of Gly particles addition could easily produce largesized pores during hydrothermal treatment because Gly particles were removed from matrix by dissolution. Formation of HA from $\alpha$-TCP was occurred at the same time under hydrothermal conditions. This chemical reaction is supposed as follows if stoichiometric HA would be prepared.

$$
10 \mathrm{Ca}_{3}\left(\mathrm{PO}_{4}\right)_{2}+6 \mathrm{H}_{2} \mathrm{O} \rightarrow 3 \mathrm{Ca}_{10}\left(\mathrm{PO}_{4}\right)_{6}(\mathrm{OH})_{2}+2 \mathrm{H}_{3} \mathrm{PO}_{4}
$$

Large amount of $\alpha$-TCP in the vessel allowed the formation of $\mathrm{H}_{3} \mathrm{PO}_{4}$ and decreased the $\mathrm{pH}$ locally in the blocks, therefore small amount of monetite was formed in the case of reaction without Gly because of the phase stability in acidic conditions. It is expected that Gly must play the role as $\mathrm{pH}$ buffer to prevent a decrease in $\mathrm{pH}$. The past reports indicated that monetite could form HA under hydrothermal conditions as following chemical reaction.

$$
10 \mathrm{CaHPO}_{4}+2 \mathrm{H}_{2} \mathrm{O} \rightarrow \mathrm{Ca}_{10}\left(\mathrm{PO}_{4}\right)_{6}(\mathrm{OH})_{2}+4 \mathrm{H}_{3} \mathrm{PO}_{4}
$$

Therefore, monetite will be removed by an additional hydrothermal treatment under neutral or basic conditions. Blocks of HA prepared in this study had the $\mathrm{Ca} / \mathrm{P}$ atomic ratio of about 1.54. This HA is nonstoichiometric HA with calcium deficient composition, so $\beta$-TCP with small amount of HA was formed after heating at $900^{\circ} \mathrm{C}$ for $3 \mathrm{~h}$ in air due to thermal decomposition of calcium deficient $\mathrm{HA}$. If $\mathrm{Ca} / \mathrm{P}$ ratio would be 1.50 , pure $\beta$-TCP specimens could be prepared with the almost same microstructure in comparison with HA blocks. From the XRD patterns, the peaks assigned to $\beta$-TCP in heated specimens showed no significant orientation, so it is assumed that formation of rod-shaped $\beta$-TCP particles from HA crystals by thermal decomposition occurred randomly in atomic scale. The morphology of the particles, pore structure and chemical composition of calcium phosphate blocks must affect bone formation in bony defects. This processing illustrated the feasibility of investigations into the effects of crystalline phases, with similar morphology, on the particles composing frameworks as well as on the porous structures.

\section{Conclusion}

The hydrothermal processing allows for the production of porous calcium phosphate ceramics consisting of rod-shaped particles. Replica method using Gly particles could give the large-sized pores over $100 \mu \mathrm{m}$, which is suitable for cells penetration into materials matrix. The entanglement of rodshaped particles could give the small sized pores less than $1 \mu \mathrm{m}$, which must be suitable for adsorption of physiologically active substances. The present method is expected to contribute to developing new bone substitutes.

Acknowledgments This work was partly supported by JSPS KAKENHI (19700404, G. Kawachi) and (21300175, K. Ioku). Powders of $\alpha$-TCP were kindly supplied from Taihei Chemical Industrial Co., Ltd., Japan. The authors thank Prof. K. Ishikawa of Kyushu University for his fruitful discussion.

\section{References}

1) H. Aoki, "Medical application of hydroxyapatite," Ishiyaku EuroAmerica, Tokyo, St. Louis (1994).

2) L. L. Hench, J. Am. Ceram. Soc., 81, 1705-1728 (1998).

3) W. Suchanek and M. Yoshimura, J. Mater. Res., 13, 94-117 (1998).

4) K. Shibuya, H. Kurosawa, H. Takeuchi and S. Niwa, J. Biomed. Mater. Res., Part B, 75B, 405-413 (2005).

5) R. K. Roeder, G. L. Converse, H. Leng and W. Yuen, J. Am. Ceram. Soc., 89, 2096-2104 (2006).

6) K. Ioku, S. Nishimura, Y. Eguchi and S. Goto, Rev. High Pressure Sci. Technol., 7, 1398-1400 (1998).

7) K. Ioku, M. Fukuhara, H. Fujimori and S. Goto, Korean J. Ceram., 5, 162-164 (1999).

8) K. Ioku, S. Yamauchi, H. Fujimori, S. Goto and M. Yoshimura, Solid State Ionics, 151, 147-150 (2002).

9) H. S. Liu, T. S. Chin, L. S. Lai, S. Y. Chiu, K. H. Chung, C. S. Chang and M. T. Luis, Ceram. Int., 23, 19-25 (1997).

10) K. Ioku, G. Kawachi, S. Sasaki, H. Fujimori and S. Goto, J. Mater. Sci., 41, 1341-1344 (2006).

11) T. Okuda, K. Ioku, I. Yonezawa, H. Minagi, Y. Gonda, G. Kawachi, M. Kamitakahara, Y. Shibata, H. Murayama, H. Kurosawa and T. Ikeda, Biomaterials, 29, 2719-2728 (2008).

12) K. Ioku, H. Misumi, H. Fujimori, S. Goto and M. Yoshimura, Proc. 5th Int. Conf. Solvo-Thermal Reactions, Ed. by R. E. Riman, NJ, USA (2002) pp. 233-236.

13) H. Yokozeki, T. Hayashi, T. Nakagawa, H. Kurosawa, K. Shibuya and K. Ioku, J. Mater. Sci.: Mater. Med., 9, 381-384 (1998).

14) E. C. Shore and E. Holmes, "An Introduction to Bioceramics," Ed. by L. L. Hench and J. Wilson, World Scientific Publishing Co., Singapore (1993) pp. 181-198.

15) M. Hori, J. Jpn. Soc. Biomater., 8, 11-22 (1990) [in Japanese].

16) K. Ioku, J. Soc. Inorg. Mater., Japan, 3, 412-418 (1996) [in Japanese].

17) T. Watanabe, G. Kawachi, M. Kamitakahara, K. Kikuta and C. Ohtsuki, J. Ceram. Soc. Japan, accepted for publication.

18) K. Ioku, T. Murakami, Y. Ikuma and M. Yoshimura, J. Ceram. Soc. Japan, 100, 1015-1019 (1992) [in Japanese].

19) K. Ishikawa, P. Duchene and S. Radin, J. Mater. Sci.: Mater. Med., 4, 165-168 (1993).

20) T. M. Leaven, "Handbook of Biomaterial Properties," Ed. by J. Black and G. Hastings, Chapman \& Hall, London (1998) pp. 15-23. 